\title{
Panel desiccation agenda
}

\author{
Rika Wada \\ Director of the Tachibana Outpatient Rehabilitation Service Center
}

My facilities provide the rehabilitation service with a Takizawa Method and the functional training which the physiotherapist is usually performing. Furthermore, I am enforcing the exercise which the author concerts the Towel Sanding and a guide training by the physiotherapist lead with an autonomous one by the patient.

Although I thought that such contents didn't especially change to the others, I present a subject for discussion in order to compensate for the international standardization of the motivative exercise for the decision of those names and clarification of a practice standard.

Next, I present a subject for discussion with an examination of the enforcement time of the motivative exercise for the international standardization. I am carrying out for 5 minutes training each for Pata and Koro at my facilities. Please check the reference ${ }^{1)-13)}$ below for the effect and situation. I will show you the enforcement situation in my presentation.

We know that we need time for the international standardization of our study, but I am looking forward to getting the participants' opinion to overcome the difficulties.

\section{Reference}

1) Rika Wada, Shigeo Takizawa, Implementation of Rehabilitation Service in the Outpatient Facility, BIOPHILIA, 2017 Volume 2017 Issue 3 90. doi.org/10.14813/ibra.2017.90

2) Rika Wada, Yoshiko Morita, Shigeo, (Taki) TAKIZAWA, The Report of the networking study for advancing home rehabilitation by KAKEN, BIOPHILIA, 2011 Volume 1 Issue 132. doi.org/10.14813/ibra.1.32

3) Rika Wada, Shigeo Takizawa, Practice of Outpatient Rehabilitation of the Takizawa Method and Motivative Exercise, BIOPHILIA, 2016 Volume 2016 Issue 2 23. doi.org/10.14813/ibra.2016.23

4) Rika Wada, Toshihiro Tachibana, Yoshiyasu Takefuji, Shigeo Takizawa, Brain Activity Measurement by Functional Near-Infrared Spectroscopy Between Motivate Exercise and Passive ROM Exercise to the Outpatients of Rehabilitation Day Care Services, BIOPHILIA, 2013 Volume 3 Issue 118. doi.org/10.14813/ibra.3.18

5) Rika Wada, Toshihiro Tachibana, Yoshiyasu Takefuji, Shigeo TAKIZAWA, EVALUATION OF THE BRAIN ACTIVITY BY fNIRS AT THE FACILITY OF TAKIZAWA METHOD ENFORCING, BIOPHILIA, 2011 Volume 1 Issue 4 4_7. doi.org/10.14813/ibra.1.4_7

6) Rika Wada, Introduction of the Program in the outpatients' rehabilitation service center to provide the rehabilitation intervention with using the motivative exercise devices, Proc. of BIOPHILIA, 2018. doi.org/10.14911/biophilia.2018.0_10(JP)

7) Rika Wada, For Establishing Rehabilitation Medical care by the motivative exercise, Proc. of BIOPHILIA, 2018. doi.org/10.14911/biophilia.2017.0_5(JP)

8) Rika Wada, For Establishing Rehabilitation Medical care by the motivative exercise, Proc. of BIOPHILIA, 2016. doi.org/10.14911/biophilia.2016.0_4 (JP)

9) Rika Wada, Toshihiro Tachibana, Takizawa Shigeo, and Yoshiyasu Takefuji, The 3rd effect evaluation of the motivative exercise enforcement, Proc. of BIOPHILIA, 2016. doi.org/10.14911/biophilia.2016.0_10 (JP)

10) Rika Wada, Toshihiro Tachibana, and Takizawa Shigeo, The 2 nd effect evaluation of the motivative exercise enforcement, Proc. of BIOPHILIA, 2015. doi.org/10.14911/biophilia.2015.0_33 (JP)

11) Rika Wada, Toshihiro Tachibana, Takizawa Shigeo, and Kenji Ushizawa, The Rehabilitation service and the effect of function maintenance, Proc. of BIOPHILIA, 2014. doi.org/10.14911/biophilia.2014.0_9

12) Rika Wada, Toshihiro Tachibana, and Takizawa Shigeo, The effect evaluation of the motivative exercise enforcement, Proc. of BIOPHILIA, 2012. doi.org/10.14911/biophilia.2012.0.16.0 (JP).

13) Rika Wada, Takizawa Method Rehabilitation, Proc. of BIOPHILIA, 2013.2.

doi.org/10.14911/biophilia.2013.2.0_142 (JP) 